\title{
The Effect of Value Add Tax on Economic Growth and Its Sources in Developing Countries
}

\author{
Seyed Hossein Ghaffarian Kolahi ${ }^{1}$ \& Zaleha Bt Mohd Noor ${ }^{2}$ \\ ${ }^{1}$ PhD Candidate, Faculty of Economic and Management, Universiti Putra Malaysia (UPM), Selangor, Malaysia \\ 2 Associate Professor, Faculty of Economic and Management, Universiti Putra Malaysia (UPM), Selangor, \\ Malaysia \\ Correspondence: Seyed Hossein Ghaffarian Kolahi, Faculty of Economic and Management, Universiti Putra \\ Malaysia (UPM), 43400 Serdang, Selangor, Malaysia. Tel: 98-915-119-7546. E-mail: Ghaffarian111@ gmail.com
}

Received: November 2, 2015

Accepted: December 3, 2015

Online Published: December 25, 2015

doi:10.5539/ijef.v8n1p217

URL: http://dx.doi.org/10.5539/ijef.v8n1p217

\begin{abstract}
Today the role of economic growth for its effect on social welfare is undeniable. For this reason, the factors influencing the economic growth are taken into account by policy makers and researchers. On the other hand, the VAT has been considered by most of the countries due to its numerous advantages and benefits. Hence, investigating how this type of tax affects the economic growth seems to be indispensable, particularly in developing countries. In this study, the effect of value added tax on economic growth was examined especially on the developing countries. In details, the effects of VAT on the economic growth of 19 developing countries for duration of 1995 to 2010 were investigated. For analysing the data, the GMM panel was employed because of the structure of the model. Afterwards, the effect of VAT through the channel of saving on the capital accumulation and productivity and ultimately the economic growth was examined. The results revealed that VAT has a negative effect on capital accumulation growth in the level; the positive effect of VAT on the level of economic growth seems to have been imposed through channels other than the increase of saving and its effect on capital accumulation.
\end{abstract}

Keywords: VAT, economic growth, capital accumulation, productivity, developing countries

\section{Introduction}

Through using the credit mechanism, VAT is administrated normally and is based on the destination principle. Sellers are allowed by the credit mechanism to claim credit for any VAT they pay by the time of buying inputs that are needed for manufacturing the goods or services that they sell. The sellers are entitled to redeem those VAT credits against any VAT that they are responsible to pay when selling the goods or services. Those VAT credits are claimed by sellers if they grant invoices for the VAT they had paid on their inputs. As follows, tax evasion is discouraged by VAT as the taxpayers themselves tend to pay and take receipts for the VAT which is paid on input purchased for enabling them to claim credit against the VAT they themselves need to pay at the point of selling their end product or service. Taxpayers themselves can give checks against one another because receipts are needed at both ends of the transaction. Such a method does not apply for other types of general sales taxes including turnover tax and retail sales taxes (Kanokpan, 2002).

The VAT can increase savings by decreasing the consumption as savings are exempted from the tax base. This means that the after-tax rate of return savings will be higher. Additionally, more savings can result in higher investment in physical capital due to its lower costs as the consumption base taxes eliminate the tax on capital income. Furthermore, savings give rise to better productivity if tax reform expands the tax base sufficiently by removing different tax preferences. As a result, an increase labour supply will be obtained as well as productivity. This occurs due to the fact that savings reduce the marginal tax rate on labour income and generate more output in the long run (Fritz et al., 1997).

In addition, an intertemporal effect will be obtained from the VAT. This effect influences the relative prices of the current consumption vs. future consumption. This implies that substitution and income effects will be generated through the tax shock. However, the net impact of these two forces on the level of aggregate private consumption is unclear, theoretically. 
The overall conclusion, lack of sufficient empirical studies especially in developing countries has mystified the diagnosis of the way the VAT affects the consumption which by itself affects the savings and capital accumulation and growth consequently.

\section{Methodology}

\subsection{Theoretical Model}

A theoretical model is developed in this section in which the growth, capital accumulation, and productivity growth effects of changes in the consumption tax rates in a two-sector endogenous growth model will be examined. By deriving all three equations based on Diamond's (1965) overlapping generation model, the issues will be dealt with. Through this model, we can justify heterogeneity for assessing both equity and efficiency considerations. In addition, by incorporating the tax design problem, the analysis will be expanded for providing a theoretical framework in order to account for the observed variation in effective VAT rates over time in the developing countries (Diamond, 1965).

It should be maintained that the model introduced here is actually a simplified version of the R\&D and growth models introduced by Romer (1990), Grossman and Helpman (1992), and Aghion and Howitt (1992). The initial model is expanded with the aim of integrating consumption taxes as well as assessing their effects on growth and its sources.

Through selecting the stream of consumption $\left(c_{1, t}\right.$ and $\left.c_{2, t+1}\right)$ subject to its life-time budget constraint, the representative consumer capitalizes on his/her life-time utility where they take the paths of interest rate, real wage and taxes as provided.

Formally:

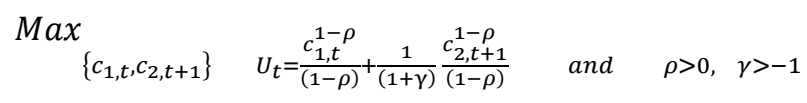

Subject to:

$$
c_{1, t}\left(1+\psi_{t}\right)+\frac{1}{1+r_{t+1}} c_{2, t+1}\left(1+\psi_{t+1}\right)=w_{t}
$$

Where:

$c_{1, t}$ is consumption of young in period $t$.

$c_{2, t+1}$ Consumption of old in period $t+1$.

$r_{t+1}$ is the interest rate.

$\psi_{t}$ is the consumption tax rate in period $t$.

$\psi_{t+1}$ is the consumption tax rate in period $t+1$.

$w_{t}$ is labor income.

$\rho$ is the intertemporal elasticity of substitution.

$\gamma$ is the exogenous rate of time preference (discount rate).

The budget constraint affirms that the present value of life-time consumption equals the present value of life-time labour income. The lagrangian function is obtained by:

$$
L_{H}=\frac{c_{1, t}^{1-\rho}}{(1-\rho)}+\frac{1}{(1+\gamma)} \frac{c_{2, t+1}^{1-\rho}}{(1-\rho)}+\lambda_{H}\left[w_{t}-c_{1, t}\left(1+\psi_{t}\right)-\frac{c_{2, t+1}\left(1+\psi_{t+1}\right)}{1+r_{t+1}}\right]
$$

The first-order conditions of the maximization problem will be attained by differentiating (3) with respect to $\mathrm{c}_{1, \mathrm{t}} \mathrm{c}_{2, \mathrm{t}+1}$, and $\lambda$. (See the Appendix A for details).

Regarding to equation (B.6) the impact of current and future consumption taxes on private savings rate is obtained by equations (4) and (5), respectively:

$$
\frac{\partial s}{\partial \psi_{t}}=\frac{\frac{1}{\rho}\left[(\rho-1)(1+\gamma)^{\frac{-1}{\rho}}\left(1+r_{t+1}\right)\left(1+\psi_{t}\right)\left(\frac{1+\psi_{t}}{1+\psi_{t+1}}\right)^{\frac{1-\rho}{\rho}}\right]}{\left(1+\psi_{t}\right)^{3}\left[-1+(1+\gamma)^{\frac{-1}{\rho}}\left(1+r_{t+1}\right)^{\frac{1-\rho}{\rho}}\left(\frac{1+\psi_{t}}{1+\psi_{t+1}}\right)^{\frac{1-\rho}{\rho}}\right]^{2}}+\frac{\left(1+\psi_{t}\right)\left[1-(1+\gamma)^{\frac{-1}{\rho}}\left(1+r_{t+1}\right)^{\frac{1-\rho}{\rho}}\left(\frac{1+\psi_{t}}{1+\psi_{t+1}}\right)^{\frac{1-\rho}{\rho}}\right]}{\left(1+\psi_{t}\right)^{3}\left[-1+\left(1+r_{t+1}\right)^{\frac{1-\rho}{\rho}}\left(\frac{1+\psi_{t}}{1+\psi_{t+1}}\right)^{\frac{1-\rho}{\rho}}\right]^{2}}
$$




$$
\frac{\partial s}{\partial \psi_{t+1}}=\frac{\left\{(1-\rho)(1+\gamma)^{\frac{-1}{\rho}}\left(1+r_{t+1}\right)^{\frac{1-\rho}{\rho}}\left(\frac{1+\psi_{t}}{1+\psi_{t+1}}\right)^{\frac{1}{\rho}}\right\}^{2}}{\left\{\rho\left(1+\psi_{t+1}\right)^{2}\left[-1+(1+\gamma)^{\frac{-1}{\rho}}\left(1+r_{t+1}\right)^{\frac{1-\rho}{\rho}}\left(\frac{1+\psi_{t}}{1+\psi_{t+1}}\right)^{\frac{1-\rho}{\rho}}\right]^{2}\right\}}
$$

Theoretically, it is implied by Equation (4) that current consumption taxes have an unclear effect on private savings rate. Undeniably, the interaction between utility parameters $(\gamma$ and $\rho)$, the interest rate $\left(r_{t+1}\right)$ and the tax structure $\left(\psi_{t} / \psi_{t+1}\right)$ will determine the effect (which measures the relative price of consumption today versus tomorrow).

Firms: Numerous similar competitive firms constitute the production side of the economy. In the economy, there are two sectors namely a goods-producing sector (modelled according to equation (6), and an R\&D sector in which additions to the stock of knowledge is made (modelled according to equation (7), as follows:

$$
\begin{gathered}
Y_{t}=\left[\left(1-f_{K}\right) K_{t}\right]^{\alpha}\left[A_{t}\left(1-f_{L}\right) L_{t}\right]^{\beta} \quad 0<\alpha<1, \beta=1-\alpha \\
A_{t}=F\left(f_{K} K_{t}, f_{L} L_{t}, A_{0}\right)
\end{gathered}
$$

Where:

$\mathrm{Y}_{\mathrm{t}}$ is output.

$\mathrm{K}_{\mathrm{t}}$ is capital.

$\mathrm{L}_{\mathrm{t}}$ is labor.

$A_{t}$ is technology.

$A_{0}$ is initial level of knowledge.

$\left(1-f_{k}\right)$ is the fraction of capital stock used in producing goods.

$\mathrm{f}_{\mathrm{k}}$ is the fraction of capital stock used in productivity.

$\left(1-f_{L}\right)$ the fraction of labour force used in producing goods.

$\mathrm{f}_{\mathrm{L}}$ the fraction of labour force used in productivity.

It is believed that Production function (6) has CRS. In order to satisfy the Inada conditions, both sides of (6) are divided by $\mathrm{L}_{\mathrm{t}}$ and $\log$ s are taken to attain:

$$
\ln \left(y_{t}\right)=\alpha \ln \left(1-f_{K}\right)+\beta \ln \left(1-f_{L}\right)+\alpha \ln k_{t}+\beta \ln a_{t}
$$

Where:

$\mathrm{y}_{\mathrm{t}}, \mathrm{k}_{\mathrm{t}}$, and $\mathrm{a}_{\mathrm{t}}$ represent output per labor, capital per labor and technology per labour, respectively.

Because it is known that:

$$
\frac{d \ln y_{t}}{d t}=\frac{\dot{y}_{t}}{y_{t}} \quad, \quad \frac{d \ln \mathrm{k}_{\mathrm{t}}}{d t}=\frac{\dot{k}_{t}}{k_{t}} \quad \text { and } \quad \frac{d \ln a_{t}}{d t}=\frac{\dot{a}_{t}}{a_{t}}
$$

It is required to differentiate (8) regarding the time:

$$
\frac{\dot{y}_{t}}{y_{t}}=\alpha \frac{\dot{k}_{t}}{k_{t}}+\beta \frac{\dot{a}_{t}}{a_{t}}
$$

Let $\left(s_{\mathrm{k}}\right)$ indicates the fraction of savings allocated to capital accumulation, and $\left(\mathrm{s}_{\mathrm{a}}\right)$ the fraction of savings allocated to knowledge accumulation. For ease, consider the mentioned fractions are provided as:

$$
\begin{array}{ccc}
s_{k}=\phi_{k} s\left(r_{t+1}, \psi_{t}, \psi_{t+1}\right) & \text { where } & \phi_{k} \in[0,1] \\
s_{a}=\phi_{a} s\left(r_{t+1}, \psi_{t}, \psi_{t+1}\right) \quad \text { where } & \phi_{a} \in[0,1] \\
\phi_{k}+\phi_{a}=1 & \\
s_{k}+s_{a}=s\left(r_{t+1}, \psi_{t}, \psi_{t+1}\right) &
\end{array}
$$

Where $s\left(r_{t+1}, \psi_{t}, \psi_{t+1}\right)$ is defined in equation (B.8) and refers to overall income devoted to savings.

\subsubsection{The Impact of VAT on Capital Accumulation}

The capital stock per unit of labour in period $(t+1)$ is given by a fraction $\left(s_{k}\right)$ of the amount saved by young individuals in period $(\mathrm{t})$; that is: 


$$
\frac{K_{t+1}}{L_{t+1}}=\frac{s_{k} w_{t} L_{t}}{L_{t+1}}
$$

where $\left(s_{k}\right)$ is defined in equation (10). Note that the population growth rate is given by $\frac{L_{t}}{L_{t+1}}=\frac{1}{1+n}$. Re-write equation (14) as follows:

$$
k_{t+1}=\frac{\phi_{k} s\left(r_{t+1}, \psi_{t}, \psi_{t+1}\right) w_{t}}{(1+n)}
$$

Substituting for $s\left(r_{t+1}, \psi_{t}, \psi_{t+1}\right)$ from equation (B.8), the per capita capital accumulation equation is given by:

$$
k_{t+1}=\frac{\phi_{k} w_{t}}{(1+n)}\left\{1-\left[\left(1+\psi_{t}\right)\left(1-\left[\frac{1+\psi_{t}}{1+\psi_{t+1}}\right]^{\frac{1-\rho}{\rho}}\left[\frac{1+\psi_{t+1}}{1+\gamma}\right]^{\frac{1}{\rho}}\left[\frac{1}{1+r_{t+1}}\right]\right)\right]^{-1}\right\}
$$

Due to the fact that the markets are competitive, the followings need to be considered:

Substituting equation (18) in (16) yields:

$$
\begin{gathered}
r_{t+1}=f^{\prime}\left(k_{t+1}\right) \\
w_{t}=f\left(k_{t}\right)-k_{t} f^{\prime}\left(k_{t}\right)
\end{gathered}
$$

$$
k_{t+1}=\frac{\phi_{k}\left[f\left(k_{t}\right)-k_{t} f^{\prime}\left(k_{t}\right)\right]}{(1+n)} \times\left\{1-\left[\left(1+\psi_{t}\right)\left(1-\left[\frac{1+\psi_{t}}{1+\psi_{t+1}}\right]^{\frac{1-\rho}{\rho}}\left[\frac{1+r_{t+1}}{1+\gamma}\right]^{\frac{1}{\rho}}\left[\frac{1}{1+r_{t+1}}\right]\right)\right]^{-1}\right\}
$$

The equation (19) can be employed to assess the impact of consumption taxes on per capita physical capital. Nevertheless, it is demonstrated by the equation that per capita capital will be influenced by taxes (and per capita productivity as displayed below) as similarly as saving is affected by taxes. They differ only in the impact as it is scaled by a constant factor as follows:

$$
\frac{\partial k_{t+1}}{\partial \psi_{t}}=\frac{\phi_{k}\left[f\left(k_{t}\right)-k_{t} f^{\prime}\left(k_{t}\right)\right]}{(1+n)}\left(\partial s / \partial \psi_{t}\right)
$$

And,

$$
\frac{\partial k_{t+1}}{\partial \psi_{t+1}}=\frac{\phi_{k}\left[f\left(k_{t}\right)-k_{t} f^{\prime}\left(k_{t}\right)\right]}{(1+n)}\left(\partial s / \partial \psi_{t+1}\right)
$$

Where $\left(\partial \mathrm{s} / \partial \psi_{\mathrm{t}}\right)$ and $\left(\partial \mathrm{s} / \partial \psi_{\mathrm{t}+1}\right)$ are derived in equations (4) and (5).

Theoretically, the impact of consumption taxes on per capita capital accumulation is, consequently, unclear. This impact depends on several factors including the interaction between utility parameters, the interest rate and the tax structure.

\subsubsection{The Impact of VAT on Productivity Growth}

The technology per unit of labour in period $(t+1)$ is given by a fraction $\left(s_{a}\right)$ of the amount saved by young individuals in period $(\mathrm{t})$ :

$$
\frac{A_{t+1}}{L_{t+1}}=\frac{s_{a} w_{t} L_{t}}{L_{t+1}}
$$

where $\left(s_{a}\right)$ is defined in equation (10). Therefore,

$$
a_{t+1}=\frac{\phi_{a} s\left(r_{t+1}, \psi_{t}, \psi_{t+1}\right) w_{t}}{(1+n)}
$$

Substituting for $s\left(r_{t+1}, \psi_{t}, \psi_{t+1}\right)$ and $w_{t}$ from equations (B.8) and (18) respectively, the per capita productivity equation is given by:

$$
a_{t+1}=\frac{\phi_{a}\left[f\left(k_{t}\right)-k_{t} f^{\prime}\left(k_{t}\right)\right]}{(1+n)} \times\left\{1-\left[\left(1+\psi_{t}\right)\left(1-\left[\frac{1+\psi_{t}}{1+\psi_{t+1}}\right]^{\frac{1-\rho}{\rho}}\left[\frac{1+r_{t+1}}{1+\gamma}\right]^{\frac{1}{\rho}}\left[\frac{1}{1+r_{t+1}}\right]\right)\right]^{-1}\right\}
$$

Note the close similarity between (19) and (24), 


$$
\frac{\partial \mathrm{a}_{\mathrm{t}+1}}{\partial \psi_{\mathrm{t}}}=\frac{\phi_{\mathrm{a}}\left[\mathrm{f}\left(\mathrm{k}_{\mathrm{t}}\right)-\mathrm{k}_{\mathrm{t}} \mathrm{f}^{\prime}\left(\mathrm{k}_{\mathrm{t}}\right)\right]}{(1+\mathrm{n})}\left(\partial s / \partial \psi_{\mathrm{t}}\right)
$$

And,

$$
\frac{\partial \mathrm{a}_{\mathrm{t}+1}}{\partial \Psi_{\mathrm{t}+1}}=\frac{\phi_{\mathrm{a}}\left[\mathrm{f}\left(\mathrm{k}_{\mathrm{t}}\right)-\mathrm{k}_{\mathrm{t}} \mathrm{f}^{\prime}\left(\mathrm{k}_{\mathrm{t}}\right)\right]}{(1+\mathrm{n})}\left(\partial \mathrm{s} / \partial \psi_{\mathrm{t}+1}\right)
$$

Where $\left(\partial \mathrm{s} / \partial \psi_{\mathrm{t}}\right)$ and $\left(\partial \mathrm{s} / \partial \psi_{\mathrm{t}+1}\right)$ are derived in equations (4) and (5).

Theoretically, the impact of consumption taxes on per capita capital productivity growth is, consequently, unclear. This impact depends on several factors including the interaction between utility parameters, the interest rate and the tax structure.

\subsubsection{The Impact of VAT on Economic Growth}

The impact of consumption taxes on growth obviously nourishes through capital accumulation and productivity growth. We know by definition that at time $(\mathrm{t}+1)$, the following is true:

$$
\dot{K}_{t}=K_{t+1}-k_{t}
$$

Where:

$\mathrm{k}_{\mathrm{t}}$ is initial endowment of capital.

$\mathrm{K}_{\mathrm{t}+1}$ is defined in equation (19).

Divide (27) by $\overline{\mathrm{K}}_{\mathrm{t}}$ :

$$
\frac{\dot{k}_{t}}{k_{t}}=\frac{k_{t+1}-k_{t}}{k_{t}}
$$

Therefore, the impact of current and future consumption taxes $\left(\psi_{t}, \psi_{t+1}\right.$, respectively) on capital accumulation will be provided by equations (29) and (30):

$$
\left(\frac{\partial\left(\dot{\mathrm{k}}_{\mathrm{t}} / \mathrm{k}_{\mathrm{t}}\right)}{\partial \psi_{\mathrm{t}}}\right)=\frac{1}{\mathrm{k}_{\mathrm{t}}}\left(\partial \mathrm{k}_{\mathrm{t}+1} / \partial \psi_{\mathrm{t}}\right)
$$

And,

$$
\left(\frac{\partial\left(\dot{\mathrm{k}}_{\mathrm{t}} / \mathrm{k}_{\mathrm{t}}\right)}{\partial \psi_{\mathrm{t}+1}}\right)=\frac{1}{\mathrm{k}_{\mathrm{t}}}\left(\partial \mathrm{k}_{\mathrm{t}+1} / \partial \psi_{\mathrm{t}+1}\right)
$$

where $\left(\partial \mathrm{K}_{\mathrm{t}+1} / \partial \psi_{\mathrm{t}}\right)$ and $\left(\partial \mathrm{K}_{\mathrm{t}+1} / \partial \Psi_{\mathrm{t}+1}\right)$ are given in equations (20) and (21), respectively. Equations (29) and (30) reveal that the sign $\left(\partial\left(\dot{\mathrm{K}}_{\mathrm{t}} / \mathrm{k}_{\mathrm{t}}\right) / \partial \psi_{\mathrm{t}}\right)$ is identical to the sign of $\left(\partial \mathrm{K}_{\mathrm{t}+1} / \partial \psi_{\mathrm{t}}\right)$, the sign of $\left(\partial\left(\dot{\mathrm{K}}_{\mathrm{t}} / \mathrm{k}_{\mathrm{t}}\right) / \partial \psi_{\mathrm{t}+1}\right)$ is also similar to the sign of $\left(\partial \mathrm{K}_{\mathrm{t}+1} / \partial \psi_{\mathrm{t}+1}\right)$.

Using the same method, we can obtain the impact of consumption taxes $\left(\psi_{t}, \psi_{t+1}\right)$ on productivity growth through equations (31) and (32):

$$
\left(\frac{\partial\left(\dot{a}_{\mathrm{t}} / \mathrm{a}_{\mathrm{t}}\right)}{\partial \psi_{\mathrm{t}}}\right)=\frac{1}{\mathrm{a}_{\mathrm{t}}}\left(\partial \mathrm{a}_{\mathrm{t}+1} / \partial \psi_{\mathrm{t}}\right)
$$

And,

$$
\left(\frac{\partial\left(\dot{a}_{t} / a_{t}\right)}{\partial \psi_{t+1}}\right)=\frac{1}{a_{t}}\left(\partial a_{t+1} / \partial \psi_{t+1}\right)
$$

Where $\left(\partial \mathrm{a}_{\mathrm{t}+1} / \partial \psi_{\mathrm{t}}\right)$ and $\left(\partial \mathrm{a}_{\mathrm{t}+1} / \partial \psi_{\mathrm{t}+1}\right)$ are given in equation (20) and (21), respectively. Equations (31) and (32) show that the sign of $\left(\partial\left(\dot{a}_{t} / a_{t}\right) / \partial \psi_{t}\right)$ is similar to the sign of $\left(\partial a_{t+1} / \partial \psi_{t}\right)$, and the sign of $\left(\partial\left(\dot{a}_{t} / a_{t}\right) / \partial \Psi_{t+1}\right)$ is identical to the sign of $\left(\partial \mathrm{a}_{\mathrm{t}+1} / \partial \psi_{\mathrm{t}+1}\right)$.

If the partial derivatives are applied to the equation (9) with respect to $\left(\psi_{\mathrm{t}}\right.$ and $\left.\psi_{\mathrm{t}+1}\right)$, it yields:

$$
\left(\frac{\partial\left(\dot{y}_{t} / y_{t}\right)}{\partial \psi_{t}}\right)=\alpha\left(\frac{\partial\left(\dot{k}_{t} / k_{t}\right)}{\partial \psi_{t}}\right)+\beta\left(\frac{\partial\left(\dot{a}_{t} / a_{t}\right)}{\partial \psi_{t}}\right)
$$

And,

$$
\left(\frac{\partial\left(\dot{y}_{t} / y_{t}\right)}{\partial \psi_{t+1}}\right)=\alpha\left(\frac{\partial\left(\dot{k}_{t} / k_{t}\right)}{\partial \psi_{t+1}}\right)+\beta\left(\frac{\partial\left(\dot{a}_{t} / a_{t}\right)}{\partial \psi_{t+1}}\right)
$$


The effects of present and future taxes on capital accumulation and on productivity growth are shown by $\left(\frac{\partial\left(\dot{\mathrm{k}}_{\mathrm{t}} / \mathrm{k}_{\mathrm{t}}\right)}{\partial \psi_{\mathrm{t}}}\right),\left(\frac{\partial\left(\dot{\mathrm{k}}_{\mathrm{t}} / \mathrm{k}_{\mathrm{t}}\right)}{\partial \psi_{\mathrm{t}+1}}\right),\left(\frac{\partial\left(\dot{a}_{\mathrm{t}} / \mathrm{a}_{\mathrm{t}}\right)}{\partial \psi_{\mathrm{t}}}\right)$, and $\left(\frac{\partial\left(\dot{\mathrm{a}}_{\mathrm{t}} / \mathrm{a}_{\mathrm{t}}\right)}{\partial \psi_{\mathrm{t}+1}}\right)$, respectively. Equations (29), (30), (31), and (32) respectively define these expressions.

The channels by which consumptions taxes influence per capita growth are represented by equations (33) and (34). Such channels are especially provided by the effect of taxes on per capita capital accumulation and on per capita productivity growth.

The worthwhile point in this model is that both channels are influenced by taxes which also affect the growth by the same token. This occurs because the impact of consumption taxes on both capital accumulation and productivity growth is feeding mostly through their respective impacts on the savings rate.

Nevertheless, the net effect of these taxes on savings, on growth and its sources is theoretically unclear according to equation (B.8). It can be concluded from a theoretical point of view that the model does not yield a precise answer on the direction of the influence although it presents a framework wherein the impact of consumption taxes on growth and its sources could be attended to.

\subsection{Econometric Model}

Estimating the following general equation with unobserved country-specific and time-specific effects was also aimed at in this study followingCaselli, Esquivel and LeFort (1996), Beck, Levine and Loayza (2000), and Rioja and Valev (2004):

Where:

$$
\ln \left(y_{i, t}\right)-\ln \left(y_{i, t-1}\right)=\alpha+\beta V A T R_{i, t}+\gamma^{\prime} X_{i, t}+\eta_{i}+\theta_{t}+\varepsilon_{i, t}
$$

$\ln \left(y_{i, t}\right)-\ln \left(y_{i, t-1}\right)$ : represents the growth rate of real GDP per capita, or physical capital per capita or productivity per capita.

$\mathrm{X}_{\mathrm{i}, \mathrm{t}} \mathrm{K} \times 1$ vector of observable independent variables.

$\gamma \quad \mathrm{K} \times 1$ vector of parameters.

$\eta_{\mathrm{i}} \quad$ Unobservable country-specific effect

$\theta_{\mathrm{t}} \quad$ Unobservable time-specific effect

$\varepsilon_{\mathrm{i}, \mathrm{t}} \quad$ Random disturbance term satisfying the following assumptions:

$\mathrm{E}\left(\varepsilon_{\mathrm{i}, \mathrm{t}}\right)=0, \mathrm{E}\left(\varepsilon_{\mathrm{i}, \mathrm{t}}^{2}\right)=\sigma_{\varepsilon}^{2}$, and $\mathrm{E}\left(\varepsilon_{\mathrm{i}, \mathrm{\varepsilon}} \varepsilon_{\mathrm{j}, \mathrm{s}}\right)=0$ if $\mathrm{i}$ j and/or $\mathrm{t} \neq \mathrm{s}$

$\mathrm{i}=1, \ldots \mathrm{N}$, where $\mathrm{N}$ refers to number of cross-sectional units (countries)

$\mathrm{t}=2, \ldots \mathrm{T}$ Number of time periods (years)

It is to be asserted that equation (50) can be re-written as:

$$
\ln \left(y_{i, t}\right)=\alpha+\ln \left(y_{i, t-1}\right)+\beta \operatorname{VATR}_{i, t}+\gamma^{\prime} X_{i, t}+\eta_{i}+\theta_{t}+\varepsilon_{i, t} \quad|\alpha|<1
$$

It is found through equation (51) that it similar (50) as estimating a dynamic equation which contains lagged dependent variable as one of the regressors.

By following Caselli, Esquivel and LeFort (1996), Beck, Levine and Loayza (2000), and Rioja and Valev (2004):, estimating regression equation is obtained.

$$
\begin{aligned}
& \ln \left(K_{i, t}\right)-\ln \left(K_{i, t-1}\right)=\alpha_{0}+\alpha_{1} V A T R_{i, t}+\alpha_{2} I N+\alpha_{3} S c+\alpha_{4} G z+\alpha_{5} O T+\alpha_{6} I n f+\alpha_{7} T T_{t}+\varepsilon_{i, t} \\
& \ln \left(P r_{i, t}\right)-\ln \left(P r_{i, t-1}\right)=\alpha_{0}+\alpha_{1} V A T R_{i, t}+\alpha_{2} I N+\alpha_{3} S c+\alpha_{4} G z+\alpha_{5} O T+\alpha_{6} I n f+\alpha_{7} T T_{t}+\varepsilon_{i, t} \\
& \ln \left(G_{i, t}\right)-\ln \left(G_{i, t-1}\right)=\alpha_{0}+\alpha_{1} V A T R_{i, t}+\alpha_{2} I N+\alpha_{3} S c+\alpha_{4} G z+\alpha_{5} O T+\alpha_{6} I n f+\alpha_{7} T T_{t}+\varepsilon_{i, t}
\end{aligned}
$$

\section{Estimation Result}

The estimation results associated with each equation has been provided separately. As stated earlier, in all the three equations, this research study relied on the same set of regressors. Prior to providing the results more meticulously, the interpretation related to each has to be presented first. It was previously highlighted through discussing Objective One that the dynamic GMM-system estimator in our study has been designed with the aim of isolating the impacts of the exogenous component of each of the explanatory variables on per capita capital growth, productivity growth, and economic growth. On condition that the considered assumptions in this section 
concerning the instruments being used in the GMM procedure were found to be precise, the casual effects of the explanatory variables on growth and its sources were isolated. Consequently, we would point out to the correlation between the exogenous component of a certain variable and the dependent variable once we mention the impacts of that variable on capital accumulation, productivity growth, or economic growth.

\subsection{Estimation Result in the Effect of VAT on Physical Capital Accumulation}

Table 1 (in the Appendix B) exhibits the results associated with the ultimate estimation using Stata11 software through xtabond 2 method in which the problems have been alleviated.

In order to investigate the residuals status, Estat abond and Estat sargan tests were accomplished and the results are presented in Table 2 and Table 3 (in the Appendix B).

It is realized through the results presented in Tables 2 and 3 that our dynamic GMM estimates are normally supported by the specification tests. Nonetheless, the sargan test of overidentifying restrictions failed to reject the null hypothesis assuming that the instruments were uncorrelated with the error term ( $\mathrm{p}$-value $=0.236$ ). Correspondingly, the tests of the serial correlation could reject the hypothesis which assumed that the error term is second-order serially correlated ( $\mathrm{p}$-value $=0.837$ ). Consequently, further support is provided for using suitable lags of the explanatory variables as instruments for the estimation.

As observed through the results, there is a statistically significant relation between the exogenous component of the lnVAT and the per capita physical capital accumulation.

Taking into account the obtained results, as we expected, the significant effect with a positive sign of lnVAT on the first lag of capital accumulation growth was consistent with the results obtained through Objective One. The reason being is that the negative effect of lnVAT on consumption in Objective One, as mentioned before, would result in the rise in saving, and capital accumulation, accordingly. This denotes that a one percentage point elevation in the VAT results in a 1.2 percentage point rise in the capital growth rate. It needs to be accentuated that the obtained results have been statistically significant at the 5 percent level.

Nonetheless, the significant and negative lnVAT on the capital accumulation growth in the level, as mentioned earlier, could be a result of the negative income effect of VAT on the future consumption which results in the reduction of saving and the latter will consequently result in the reduction of capital accumulation. However, this effect is different in the studied countries but all together it yields such a result.

\subsection{Estimation Result in the Effect of VAT on the Productivity Growth}

Table 4 (in the Appendix B) demonstrates the results of the ultimate estimation using Stata11 software through xtabond2 method in which the problems have been alleviated.

In order to investigate the residuals status, Estat abond and Estat sargan tests were conducted and the results are presented in Tables 5 and Table 6 (in the Appendix B).

It is revealed through the results tabulated in Tables 5 and 6 that our dynamic GMM estimates are normally supported by the specification tests. However, the sargan test of overidentifying restrictions failed to reject the null hypothesis which assumed that the instruments were uncorrelated with the error term (p-value $=0.938$ ). Correspondingly, the tests of serial correlation could reject the hypothesis which assumed that the error term is second-order serially correlated ( $\mathrm{p}$-value $=0.650$ ). Accordingly, further support is provided for using suitable lags of the explanatory variables as instruments for the estimation.

The results of the GMM-System estimator indicated a statistically significant relation between the exogenous component of the lnVAT and productivity growth (at the $1 \%$ level of significance). As shown by the size of the estimated coefficient, a rise of one percentage point in the lnVAT would result in the productivity growth up by around $4.8 \%$. As stated earlier, this positive and significant level might be for the following reason: in case the tax reform can sufficiently expand the tax base through eliminating diverse tax preferences, it may result in a rise in the labour supply, and productivity subsequently. The reason being is that it permits a decline in the marginal tax rate on labour income and more output in the long run (Fritz et al., 1997).

\subsection{Estimation Result in the Effect of VAT on the Economic Growth}

Table 7 (in the Appendix B) displays the results of the ultimate estimation using Stata11 software through xtabond 2 method in which the problems have been alleviated.

In order to investigate the residuals status, Estat abond and Estat sargan tests were conducted and the results are presented in Table 8 and Table 9 (in the Appendix B).

The results shown in Tables 8 and 9 reveal that our dynamic GMM estimates are normally supported by the 
specification tests. Yet, the sargan test of overidentifying restrictions failed to reject the null hypothesis which assumed that the instruments were uncorrelated with the error term ( $\mathrm{p}$-value $=0.981$ ). Therefore, the tests of serial correlation could reject the hypothesis which assumed that the error term is second-order serially correlated ( $\mathrm{p}$-value $=0.372$ ). As a result, further support is provided for using suitable lags of the explanatory variables as instruments for the estimation.

The results (Table 7) reveal a statistically significant relation between the exogenous component of the lnVAT and the economic growth. The significance of this coefficient in level with a positive sign is because of the increase in productivity as well as the fact that the VAT transfers the tax burden from the producer to the consumer.

Nevertheless, the significant correlation between VAT and economic growth in the first lag can be justified as follows, considering the results of Objective One and Objective Two:

The increase in the VAT would result in the reduction in the consumption that consequently causes an upsurge in saving which would increase the capital accumulation. Because the share of consumption in the Total Demand Equation is further than the share of investment in the mentioned equation, the overall combination of consumption and investment would result in the reduction of Total Demand or the production. As a result, economic growth would be decreased.

This means that a one percentage point upsurge in the lnVAT could result in 4.6 percentage point rise in the economic growth in the level. The result was statistically significant at the 1 percent level. Moreover, in the first lag, a one percent surge in lnVAT resulted in a statistically significant reduction of $3.8 \%$ in the economic growth in the $1 \%$ level.

\section{Conclusion and Discussion}

\subsection{Value Added Tax and Capital Accumulation}

The significant and negative lnVAT on the capital accumulation growth in the level might be resulted from the negative income effect of VAT on the future consumption that leads to an increase of saving. The latter would therefore give rise to the decline of capital accumulation. Nevertheless, this effect is different in the studied countries but all together it yields such a result.

Taking into account the obtained results, as we expected, the significant effect with a positive sign of lnVAT on the first lag of capital accumulation growth was congruent with the results attained after addressing Objective One. This happens because the negative effect of lnVAT on consumption in Objective One might increase saving, and capital accumulation, accordingly.

It is of note that the tax system which replaces the labor taxes with consumption taxes would generate more capital economy with rather more wealth inequality (Markku, 2011).

\subsection{Value Added Tax and Productivity Growth}

The results of the GMM-System estimator indicated a statistically significant relation between the exogenous component of the lnVAT and productivity growth (at the $1 \%$ level of significance). As shown by the size of the estimated coefficient, a rise of one percentage point in the lnVAT might result in the productivity growth up by around $4.8 \%$. As mentioned at an earlier point, this positive and significant level would be a result of the following reason: in the event the tax reform can sufficiently expand the tax base by eliminating diverse tax preferences, it might lead to an increase of the labor supply, and consequently the productivity. This happens because it allows a fall in the marginal tax rate on labor income and more output in the long run (Fritz, Thornton, \& Bibbee, 1997).

Consumption taxes seem to decline the probability of voluntary unemployment. Such results disrupt the equivalence between these labor-income and consumption taxes whereupon the optimal tax literature is premised, offering the potential for a welfare-improving government response, as shown by their simple theoretical model (Blumkin, Ruffle, \& Ganun, 2012).

\subsection{Value Added Tax and Economic Growth}

The significant correlation between VAT and economic growth in the first lag can be justified by considering the results of Objective One and Objective Two. In fact, the increase in the VAT would result in the reduction in the consumption that consequently causes an upsurge in saving which would increase the capital accumulation. Because the share of consumption in the Total Demand Equation is further than the share of investment in the mentioned equation, the overall combination of consumption and investment would result in the reduction of Total Demand or the production. As a result, economic growth would be decreased. The consumption growth 
was hindered if the government debt was financed through consumption taxation. Subsequently, the economic growth would be hindered according to consumption-led-growth theory (Georgiou, 2009).

\section{References}

Aghion, P., \& Howitt, P. (1992). A Model of Growth through Creative Destruction. Econometrica, 60, 323-351. http://dx.doi.org/10.2307/2951599

Arellano, M., \& Bond, S. (1991). Some Tests of Specivication for Panel Data: Monte Carlo Evidence and An Application to Employment Equtions. Review of Economic Studies, 58, 227-297. http://dx.doi.org/10.2307/2297968

Arellano, M., \& Bover, O. (1995). Another Look at the Instrumental Variable Estimation of Error component Models. Jourmal of Ecomometrics, 68, 29-52. http://dx.doi.org/10.1016/0304-4076(94)01642-d

Beck, T., Levine, R., \& Loayza, N. (2000). Finance and the Sources of Growth. Journal of Financial Economics, 58, 261-300. http://dx.doi.org/10.1016/S0304-405X(00)00072-6

Blumkin, T., Ruffle, B. J., \& Ganun, Y. (2012). Are income and consumption taxes ever really equivalent? Evidence from a real-effort experiment with real goods. European Economic Review, 56(6), 1200-1219. http://dx.doi.org/10.1016/j.euroecorev.2012.06.001

Caselli, F., Esquivel, G., \& LeFort, F. (1996). Reopening the Iconvergence Debate: A New Look at Cross-Country Growth Empirics. Jornal of Economic Growth, 1, 363-389. http://dx.doi.org/10.1007/BF00141044

Diamond, P. (1965). National Debt in a Neoclassical Growth Model. American Economic Review, 55, 1126-1150.

Fritz, W. L., Thornton, J., \& Bibbee, A. (1997). Taxation and Economic Performance. Organisation For Economic Co-Operation And Development: Working Papers No. 176.

Georgiou, M. N. (2009). The Impact of Consumption Tax Rate on Consumption - A Panel Data Analysis for European Countries (1995-2007). SSRN eLibrary. http://dx.doi.org/10.2139/ssrn.1529242

Grossman, G. M., \& Helpman, E. (1992). Innovation and growth in the global economy. MIT press.

Kanokpan, L. A. (2002). How can Cambodia, Lao PDR, Mayanmar, and Viet Nam Cope with Revenue Lost. Asian Development Bank.

King, R. G., \& Levine, R. (1994). Capital fundamentalism, economic development, and economic growth. Carnegie-Rochester Conference Series on Public Policy, 40, 259-292. http://dx.doi.org/10.1016/0167-2231(94)90011-6

Markku, L. (2011). Labor or consumption taxes? An application with a dynamic general equilibrium model with $\begin{array}{lllll}\text { heterogeneous } \quad \text { agents. } & \text { Economic } & \text { Modelling, } & \text { 28, } & \text { 1984-1992. }\end{array}$ http://dx.doi.org/10.1016/j.econmod.2011.03.029

Rioja, F., \& Valev, N. (2004). Finance and the Sources of Growth at Various Stages of Economic Development. Economic Inquiry, 42, 127-140. http://dx.doi.org/10.1093/ei/cbh049

Romer, P. (1990). Endogenous Tecnological Change. Journal of Political Economy, 98, S71-S102. http://dx.doi.org/10.1086/261725

\section{Appendix A}

With respect to $c_{1, t} c_{2, t+1}$, and $\lambda$ the first-order conditions of the maximization problem are obtained be differentiating equation (8) as follows:

$$
\begin{gathered}
\mathrm{c}_{1, \mathrm{t}}: \quad \lambda=\frac{\mathrm{c}_{1, \mathrm{t}}^{-\rho}}{\left(1+\psi_{\mathrm{t}}\right)} \\
\mathrm{c}_{2, \mathrm{t}+1}: \quad \lambda=\frac{\mathrm{c}_{2, \mathrm{t}+1}^{-\rho}\left(1+\mathrm{r}_{\mathrm{t}+1}\right)}{(1+\gamma)\left(1+\psi_{\mathrm{t}+1}\right)} \\
\lambda: \quad \mathrm{w}_{\mathrm{t}}-\mathrm{c}_{1, \mathrm{t}}\left(1+\psi_{\mathrm{t}}\right)-\frac{\mathrm{c}_{2, \mathrm{t}+1}\left(1+\psi_{\mathrm{t}+1}\right)}{\left(1+\mathrm{r}_{\mathrm{t}+1}\right)}=0
\end{gathered}
$$


From (B.1) and (B.2) we get the following Euler equation:

$$
\frac{c_{2, t+1}}{c_{1, t}}=\left[\left(\frac{1+r_{t+1}}{1+\gamma}\right)\left(\frac{1+\psi_{t}}{1+\psi_{t+1}}\right)\right]^{\frac{1}{\rho}}
$$

Substituting (B.4) into (B.3) and solving for $\mathrm{c}_{1, \mathrm{t}}$ :

$$
c_{1, t}=\left\{\frac{w_{t}}{\left(1+\psi_{t}\right)\left(1-\left[\frac{1+\psi_{t}}{1+\psi_{t+1}}\right]^{\frac{1-\rho}{\rho}}\left[\frac{1+r_{t+1}}{1+\gamma}\right]^{\frac{1}{\rho}}\left[\frac{1}{1+r_{t+1}}\right]\right)}\right\}
$$

Equation (B.5) demonstrates that the fraction of income the individual consumes in the first period is determined by the interest rate and the consumption tax rates. From (B.4) and (B.5), we can solve for $c_{2, t+1}$ :

$$
c_{2,1+t}=\left\{\frac{w_{t}\left(\left[\frac{1+\psi_{t}}{1+\psi_{t+1}}\right]^{\frac{1-\rho}{\rho}}\left[\frac{1+r_{t+1}}{1+\gamma}\right]^{\frac{1}{\rho}}\right)}{\left(1+\psi_{t+1}\right)\left(1-\left[\frac{1+\psi_{t}}{1+\psi_{t+1}}\right]^{\frac{1-\rho}{\rho}}\left[\frac{1+r_{t+1}}{1+\gamma}\right]^{\frac{1}{\rho}}\left[\frac{1}{1+r_{t+1}}\right]\right)}\right\}
$$

If $s\left(r_{t+1}, \psi_{t}, \psi_{t+1}\right)$ stand for the fraction of income saved, then (B.5) implies:

$$
c_{1, t}=\left[1-s\left(r_{t+1}, \psi_{t}, \psi_{t+1}\right)\right] w_{t}
$$

Substituting for $c_{1, t}$ from (B.5) and solving for $s\left(r_{t+1}, \psi_{t}, \psi_{t+1}\right)$ we will obtain:

$$
s\left(r_{t+1}, \psi_{t}, \psi_{t+1}\right)=1-\left\{\left(1+\psi_{t}\right)\left(1-\left[\frac{1+\psi_{t}}{1+\psi_{t+1}}\right]^{\frac{1-\rho}{\rho}}\left[\frac{1+r_{t+1}}{1+\gamma}\right]^{\frac{1}{\rho}}\left[\frac{1}{1+r_{t+1}}\right]\right)\right\}^{-1}
$$

\section{Appendix B}

Table 1. The xtabond2 method results about value added tax and capital accumulation

\begin{tabular}{ccccc}
\hline Variables & Coefficient & Std. error & $\mathrm{Z}$ & $\mathrm{p}$-value \\
\hline Ln VAT & -.0130947 & .006081 & -2.15 & 0.044 \\
L1 & .0127568 & .0049645 & 2.57 & 0.019 \\
LnIN & .4443996 & .630085 & 7.05 & 0.000 \\
L1 & -.3938192 & .0729879 & -5.40 & 0.000 \\
Gz & -.0005657 & .0012686 & -0.45 & 0.661 \\
L1 & -.0008392 & .0013927 & -0.60 & 0.554 \\
SC & .0009265 & .0016338 & 0.57 & 0.577 \\
L1 & -.003452 & .0029872 & -1.16 & 0.262 \\
OT & .0002826 & .0003918 & 0.72 & 0.480 \\
L1 & .0003598 & .0008273 & 0.43 & 0.669 \\
Yr-dv13 & -.0012539 & .0035891 & -0.35 & 0.731 \\
Yr-dv14 & -.001642 & .0039423 & -0.42 & 0.682 \\
Year & -.0014794 & .0006001 & -2.47 & 0.023 \\
\hline
\end{tabular}

Table 2. Arellano-Bond test for zero autocorrelation in first-differenced errors

\begin{tabular}{lll}
\hline Ordere & $\mathrm{Z}$ & $\mathrm{p}$-value \\
\hline 1 & -2.92 & 0.003 \\
2 & -0.21 & 0.837 \\
\hline H0: no autocorrelation & & \\
\hline
\end{tabular}


Table 3. Sargan test of overidentifying restrictions

\begin{tabular}{ll}
\hline Chi2(94) & 103.52 \\
Prob $>$ chi2 & 0.236 \\
\hline H0: overidentifying restrictions are valid & \\
\hline
\end{tabular}

Table 4. Xtabond2 results about VAT and productivity growth

\begin{tabular}{lllll}
\hline Variables & Coefficient & Std. error & Z & p-value \\
\hline Ln VAT & .04807 & .0134227 & 3.58 & 0.002 \\
L1 & -.0429458 & .0139954 & -3.07 & 0.006 \\
LnIN & -.501802 & .260513 & -1.92 & 0.065 \\
L1 & .488072 & .424365 & 1.15 & 0.266 \\
Gz & -.0054132 & .0035227 & -1.54 & 0.141 \\
L1 & .0051057 & .0028704 & 1.78 & 0.091 \\
SC & .0061065 & .0081427 & 0.75 & 0.462 \\
L1 & -.003278 & .0072378 & -0.45 & 0.656 \\
OT & .0028224 & .0011551 & 2.44 & 0.024 \\
L1 & -.001543 & .0013926 & -1.11 & 0.282 \\
Yr-dv13 & .0169374 & .0065887 & 2.57 & 0.019 \\
Yr-dv14 & .0037529 & .0086952 & 0.43 & 0.671 \\
Year & .0074754 & .0022755 & 3.29 & 0.004 \\
\hline
\end{tabular}

Table 5. Arellano-Bond test for zero autocorrelation in first-differenced errors

\begin{tabular}{lll}
\hline Ordere & $\mathrm{Z}$ & $\mathrm{p}$-value \\
\hline 1 & -2.89 & 0.004 \\
2 & 0.45 & 0.650 \\
\hline H0: no autocorrelation & & \\
\hline
\end{tabular}

Table 6. Sargan test of overidentifying restrictions

\begin{tabular}{ll}
\hline Chi2(94) & 73.90 \\
Prob $>$ chi2 & 0.938 \\
\hline H0: overidentifying restrictions are valid & \\
\hline
\end{tabular}

Table 7. Xtabond2 results about value added tax and economic growth

\begin{tabular}{lllll}
\hline Variables & Coefficient & Std. error & Z & p-value \\
\hline LnVAT & .0462347 & .0133832 & 3.45 & 0.003 \\
L1 & -.0380719 & .0131005 & -2.91 & 0.009 \\
LnIN & -.1295869 & .1400616 & -0.93 & 0.366 \\
Gz & -.0054291 & .0034117 & -1.59 & 0.128 \\
L1 & .0044452 & .0030172 & 1.47 & 0.157 \\
SC & .0072683 & .0097636 & 0.74 & 0.466 \\
L1 & -.0050317 & .0085144 & -0.59 & 0.562 \\
OT & .0029332 & .0011294 & 2.60 & 0.018 \\
L1 & -.0015583 & .0013704 & -1.14 & 0.270 \\
Yr-dv13 & .0161648 & .0054304 & 2.98 & 0.008 \\
Yr-dv14 & .0022572 & .0085922 & 0.26 & 0.796 \\
Year & .0074839 & .00235 & 3.18 & 0.005 \\
\hline
\end{tabular}

Table 8. Arellano- Bond test for zero autocorrelation in first-differenced errors

\begin{tabular}{lll}
\hline Ordere & $\mathrm{Z}$ & $\mathrm{p}$-value \\
\hline 1 & -2.76 & 0.006 \\
2 & 0.89 & 0.372 \\
\hline H0: no autocorrelation & & \\
\hline
\end{tabular}


Table 9. Sargan test of overidentifying restrictions

\begin{tabular}{ll}
\hline Chi2(94) & 67.71 \\
Prob $>$ chi2 & 0.981 \\
\hline H0: overidentifying restrictions are valid & \\
\hline
\end{tabular}

\section{Copyrights}

Copyright for this article is retained by the author(s), with first publication rights granted to the journal.

This is an open-access article distributed under the terms and conditions of the Creative Commons Attribution license (http://creativecommons.org/licenses/by/3.0/). 